\title{
Erratum
}

\section{Stereoselective Total Synthesis of Obolactone via Prins Cyclization}

Gowravaram Sabitha,* M. Nagendra Prasad, K. Shankaraiah, Jhillu S. Yadav Synthesis 2010, 1171.

In the experimental procedures, for compounds $\mathbf{6}, \mathbf{9}, \mathbf{1 0}, \mathbf{1 1}, \mathbf{1 2}, 13$ and 14, the C-4 stereochemistry was given as ' $S$ ', but it should be ' $R$ ' and for compound $\mathbf{5}$, the C-4 stereochemistry was given as ' $R$ ', but it should be ' $S$ '. 